Argonne

ANL/DIS-11-9

\title{
Developing an Operational Capabilities Index of the Emergency Services Sector
}

Decision and Information Sciences Division 


\begin{abstract}
About Argonne National Laboratory
Argonne is a U.S. Department of Energy laboratory managed by UChicago Argonne, LLC under contract DE-AC02-06CH11357. The Laboratory's main facility is outside Chicago, at 9700 South Cass Avenue, Argonne, Illinois 60439. For information about Argonne and its pioneering science and technology programs, see www.anl.gov.
\end{abstract}

\title{
Availability of This Report
}

This report is available, at no cost, at http://www.osti.gov/bridge. It is also available on paper to the U.S. Department of Energy and its contractors, for a processing fee, from:

U.S. Department of Energy

Office of Scientific and Technical Information

P.O. Box 62

Oak Ridge, TN 37831-0062

phone (865) 576-8401

fax (865) 576-5728

reports@adonis.osti.gov

\begin{abstract}
Disclaimer
This report was prepared as an account of work sponsored by an agency of the United States Government. Neither the United States Government nor any agency thereof, nor UChicago Argonne, LLC, nor any of their employees or officers, makes any warranty, express or implied, or assumes any legal liability or responsibility for the accuracy, completeness, or usefulness of any information, apparatus, product, or process disclosed, or represents that its use would not infringe privately owned rights. Reference herein to any specific commercial product, process, or service by trade name, trademark, manufacturer, or otherwise, does not necessarily constitute or imply its endorsement, recommendation, or favoring by the United States Government or any agency thereof. The views and opinions of document authors expressed herein do not necessarily state or reflect those of the United States Government or any agency thereof, Argonne National Laboratory, or UChicago Argonne, LLC.
\end{abstract}


ANL/DIS-11-9

\section{Developing an Operational Capabilities Index of the Emergency Services Sector}

by

M.J. Collins, L.K. Eaton, Z.M Shoemaker, R.E. Fisher,

S.N. Veselka, K.E. Wallace, and F.D. Petit.

Decision and Information Sciences Division, Argonne National Laboratory

August 2011 



\section{CONTENTS}

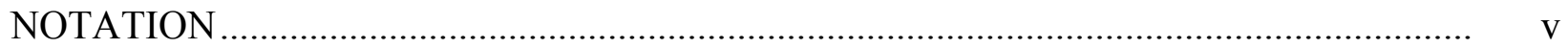

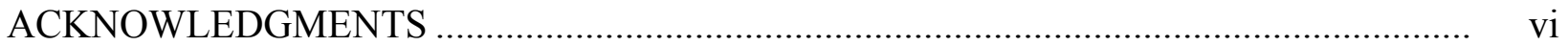

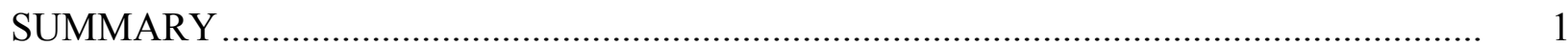

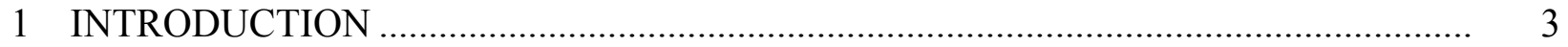

2 EMERGENCY SERVICES SECTOR …............................................................

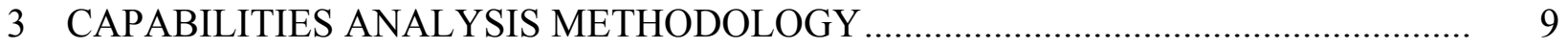

3.1 Information Organization and Data Collection ................................................ 10

3.2 Index Calculation .................................................................................... 13

3.3 Index Visualization and Comparison .................................................................. 19

4 INDEX USE

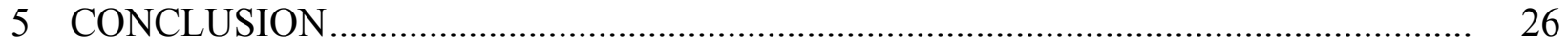

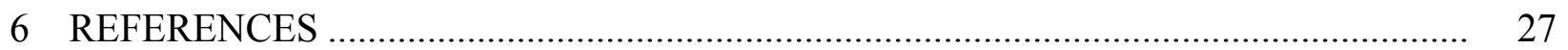

APPENDIX: COMPONENTS OF LEVELS 1, 2, AND 3 OF ESSCI ................................ A-1

\section{TABLES}

1 Roles and Responsibilities Associated with ESS Functions and Disciplines ................... 7

2 Roles and Responsibilities Associated with ESS Specialized Capabilities ..................... 7

3 Level 1 and 3 Components Constituting the ESSCI.............................................. 11

4 Example of Value Assessments from Experts ..................................................... 14

5 Level 4 Hazard Consequence Analysis Index ....................................................... 15

6 Level 3 Identification of Hazards Capability Index .............................................. 15

7 Level 2 Emergency Management Operational Capabilities Index ................................. 16 


\section{TABLES (CONT.)}

8 Level 1 Emergency Management Index ………....................................................... 17

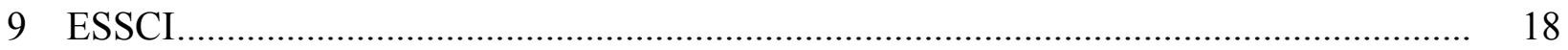

\section{FIGURES}

1 Risk Management Process ................................................................................................ 6

2 Pyramidal Organization of Levels of Information........................................................... 10

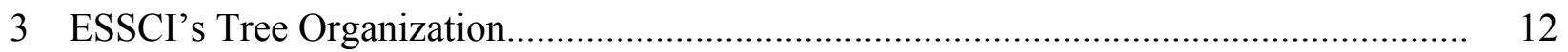

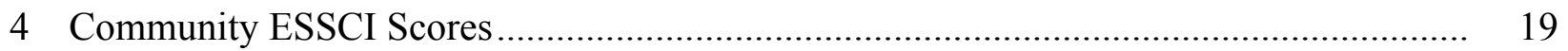

5 Community ESSCI Scores Shown by Element …………............................................. 20

6 Operational Capability Scores for Emergency Management............................................ 21

7 Importance of Components with Regard to Overall Emergency Management Operational Capabilities............................................................................................... 21

8 ESSCI Dashboard — Overview Screen....................................................................... 22

9 ESSCI Dashboard — Fire Services/Communication ......................................................... 23

10 ESSCI Dashboard — Brief Review .......................................................................... 24 


\section{NOTATION}

CI critical infrastructure

DHS

U.S. Department of Homeland Security

ECIP

Enhanced Critical Infrastructure Protection (program)

ESS

Emergency Services Sector

ESSCI

Emergency Services Sector Capabilities Index

HSPD

MAUT

Homeland Security Presidential Directive

PPD

multi attribute utility theory

RI

Presidential Policy Directive

QA

resilience index

VI

quality assurance

vulnerability index 


\section{ACKNOWLEDGMENTS}

The authors gratefully acknowledge the contributions of many people who helped bring this project to its current state of development, including the U.S. Department of Homeland Security. The authors are particularly thankful to Kurtis Michaud, Ray Moellers, Kory Whalen, and Charlie Payne, without whom all of this work would not have been possible. Their leadership and dedication inspired the Argonne National Laboratory team.

The authors also want to thank Alan Amano, Michael Fagel, Edward Buikema, Ed Cooper, Richard Mckee, and their Argonne colleagues who contributed to the methodology and weighting process. 


\title{
DEVELOPING AN OPERATIONAL CAPABILITIES INDEX OF THE EMERGENCY SERVICES SECTOR
}

\author{
by \\ M.J. Collins, L.K. Eaton, Z.M Shoemaker, R.E. Fisher, \\ S.N. Veselka, K.E. Wallace, and F.D. Petit
}

\begin{abstract}
SUMMARY
In order to enhance the resilience of the Nation and its ability to protect itself in the face of natural and human-caused hazards, the ability of the critical infrastructure (CI) system to withstand specific threats and return to normal operations after degradation must be determined. To fully analyze the resilience of a region and the CI that resides within it, both the actual resilience of the individual CI and the capability of the Emergency Services Sector (ESS) to protect against and respond to potential hazards need to be considered. Thus, a regional resilience approach requires the comprehensive consideration of all parts of the CI system as well as the characterization of emergency services. This characterization must generate reproducible results that can support decision making with regard to risk management, disaster response, business continuity, and community planning and management. To address these issues, Argonne National Laboratory, in collaboration with the U.S. Department of Homeland Security (DHS) Sector Specific Agency - Executive Management Office, developed a comprehensive methodology to create an Emergency Services Sector Capabilities Index (ESSCI).
\end{abstract}

The ESSCI is a performance metric that ranges from 0 (low level of capabilities) to 100 (high). Because an emergency services program has a high ESSCI, however, does not mean that a specific event would not be able to affect a region or cause severe consequences. And because a program has a low ESSCI does not mean that a disruptive event would automatically lead to serious consequences in a region. Moreover, a score of 100 on the ESSCI is not the level of capability expected of emergency services programs; rather, it represents an optimal program that would rarely be observed. The ESSCI characterizes the state of preparedness of a jurisdiction in terms of emergency and risk management. Perhaps the index's primary benefit is that it can systematically capture, at a given point in time, the capabilities of a jurisdiction to protect itself from, mitigate, respond to, and recover from a potential incident. On the basis of this metric, an interactive tool - the ESSCI Dashboard - can identify scenarios for enhancement that can be implemented, and it can identify the repercussions of these scenarios on the jurisdiction. It can assess the capabilities of law enforcement, firefighting, search and rescue, emergency medical services, hazardous materials response, dispatch/911, and emergency management services in a given jurisdiction and it can help guide those who need to prioritize what limited resources should be used to improve these capabilities.

Furthermore, this tool can be used to compare the level of capabilities of various jurisdictions that have similar socioeconomic characteristics. It can thus help DHS define how it can support risk reduction and community preparedness at a national level. 
This tool aligns directly with Presidential Policy Directive 8 by giving a jurisdiction a metric of its ESS's capabilities and by promoting an interactive approach for defining options to improve preparedness and to effectively respond to a disruptive event. It can be used in combination with other CI performance metrics developed at Argonne National Laboratory, such as the vulnerability index and the resilience index for assessing regional resilience. 


\section{INTRODUCTION}

Critical infrastructure facilities are vital to the functioning of society. Their criticality makes it very important to maintain their operations, assure their resilience, decrease their vulnerabilities, and reduce any negative consequences that might result from their failures. Although completing the tasks necessary to fulfill these critical infrastructure (CI) requirements can be difficult and arduous, the results are imperative: Enhancing the protection and resilience of CI facilities helps ensure a more well-protected and resilient Nation.

Of the 18 CI sectors defined in the National Infrastructure Protection Plan (DHS 2009a), one sector or asset is particularly important when it comes to ensuring and ultimately enhancing the Nation's protection and resilience: the Emergency Services Sector (ESS). As is the case for other CI assets, the resilience of ESS assets directly affects the resilience of a specific region. However, the resilience of ESS assets is also an integral part of the resilience of all CI facilities. In the ESS, the capabilities of all first responders are combined - and they constitute a key factor in the ability of a CI to adapt to, react to, and recover from a crisis. As the meaning and importance of resilience are debated, it is vital to identify core functions for resilience management. A highly functioning ESS captures many of those necessary functions.

Furthermore, as highlighted in Presidential Policy Directive 8 (PPD-8) of March 30, 2011, National Preparedness, to strengthen the security and resilience of the United States, it is important to promote the systemic preparation for the man-made and natural threats that pose the greatest risk to the security of the Nation (DHS 2011). To achieve this level of preparedness and ensure it is effective, the effort must involve the identification of the core capabilities needed to prevent, protect against, mitigate the effects of, respond to, and recover from the threats that pose the greatest security risk to the United States (DHS 2011).

PPD-8 indicates that it is vital to have a tool that helps a jurisdiction characterize and assess what capabilities it has for managing a risk and/or crisis. This tool should reveal the state of the situation at a given time and propose measures that can be implemented to improve a jurisdiction's overall capability level.

This report describes a comprehensive methodology that was developed to assess ESS capabilities and propose options for consideration. The methodology defines a performance metric that measures the capabilities of a single jurisdiction's ESS to help it respond to an event and can also be combined with other indices (developed at Argonne National Laboratory) to assess the resilience of a community or region. When the ESS's unique response and recovery role is addressed, researchers can account for the positive impact that a robust ESS would have on a region's or system's ability to more quickly respond to and recover from natural or humancaused hazards or, conversely, account for the negative impact that a low-functioning ESS would have on the CI within its jurisdiction.

After an overview of the ESS, this report presents the methodology developed for estimating the the capabilities of a jurisdiction to provide emergency services. The modes of calculation, as well 
as the tool used for proposing options for consideration, are shown. Finally, it describes how this index can be used in conjunction with other tools to assess regional preparedness and resilience. 


\section{EMERGENCY SERVICES SECTOR}

ESS constitutes one of the 18 CI sectors defined by Homeland Security Presidential Directive 7 (HSPD-7) (The White House 2003). Five core categories of assets (i.e., disciplines or subsectors) are grouped in this sector (DHS 2008): Law Enforcement; Fire, Rescue, and Emergency Services; Emergency Medical Services; Emergency Management; and Public Works.

The Law Enforcement subsector includes the facilities and assets used by sworn officers to protect the public, enforce the law, conduct criminal investigations, gather evidence, and apprehend perpetrators of crime. They include local, state, and federal assets (DHS 2008).

The Fire, Rescue, and Emergency Services subsector includes the assets used by trained personnel in fire suppression, fire prevention, hazardous materials (HAZMAT) control, emergency rescue, building code enforcement, and public fire safety education. The assets also include those used to respond to chemical/biological/radiological incidents. They include local, state, and federal assets (DHS 2008).

The Emergency Medical Services subsector includes the facilities, apparatus, and equipment used by trained medical response personnel for providing immediate medical attention during critical indents and for transporting triage patients to enhanced medical service facilities. In addition, this subsector includes the administrative functions of EMS, including billing, report storage, policy development, and executive administration (DHS 2008).

The Emergency Management subsector includes the facilities and assets that help provide mitigation, prevention, preparedness (including planning, training, and exercising), response (including coordination, resource acquisition, and resource prioritization), and recovery efforts and that also help provide the public with information before, during, and after disasters and catastrophic events (DHS 2008).

The Public Works subsector includes resource management and acquisition functions that are often leveraged by the Emergency Management subsector in response and recovery missions following an incident. These functions include essential emergency response services, such as assessing damage to buildings, roads and bridges; clearing, removing, and disposing of debris; restoring utility services; and managing emergency traffic (DHS 2010a). This subsector is specific to the disaster-related functions of public works and not the steady-state functions of the organizations.

ESS is critical to the United States because, by definition, its incapacitation or destruction would have a debilitating effect on the Nation's overall security, economic security, public health, public safety, or any combination of these (DHS 2010b). The sector's importance is reinforced by the fact that it is the Nation's first line of defense for preventing and mitigating the risk from physical and cyber attacks and man-made and natural disasters (DHS 2010a). The sector plays an integral part in each phase of the risk management process undertaken at the local and national levels (Figure 1). 


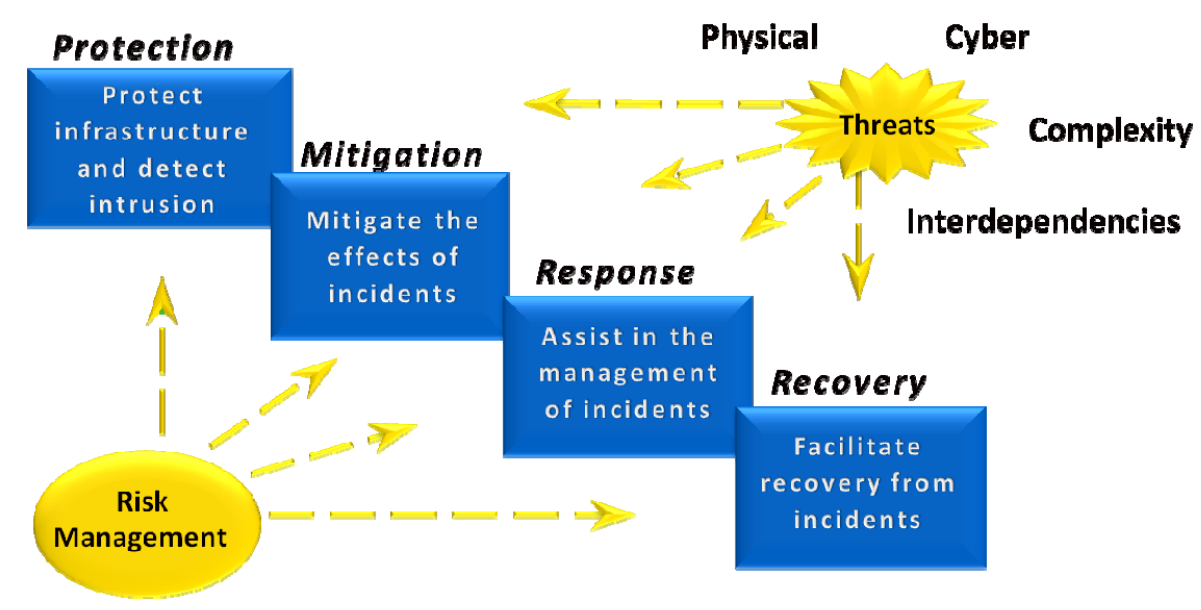

FIGURE 1 Risk Management Process (Fisher et al. 2003)

The primary missions of ESS are fourfold: to save lives, protect property and the environment, assist communities affected by disasters, and aid in recovery during emergencies (DHS 2010a). To fulfill these responsibilities, ESS must be able to help prepare other CI facilities protect themselves and mitigate potential natural and man-made hazards. ESS assets are also the first ones to lead or help in managing the response to incidents and crises and to facilitate recovery from incidents.

ESS can thus be viewed as a cornerstone of risk management that has a wide range of functions resulting from the variety in its roles and responsibilities. Some of these roles and responsibilities are specific to the five disciplines or subsectors that make up ESS (Table 1). These roles and responsibilities, however, are not the only ones undertaken by ESS. Different specialized capabilities that exist within a discipline or are shared by some or all of them include:

- HAZMAT response,

- Search and rescue,

- Explosive ordnance disposal,

- Special weapons and tactics and tactical operations,

- Aviation units, and

- Public safety answering points.

ESS has specific roles and responsibilities related to these specialized capabilities (Table 2).

To characterize the capabilities of a jurisdiction in terms of risk management, it is thus essential to assess the capabilities of the ESS within that jurisdiction. To do this, all ESS's roles and responsibilities should be considered. 


\section{TABLE 1 Roles and Responsibilities Associated with ESS Functions and Disciplines (DHS 2010a)}

\begin{tabular}{|ll|}
\hline \multicolumn{1}{|c|}{ Function / Discipline } & \multicolumn{1}{c|}{ Roles and Responsibilities } \\
\hline Law Enforcement & $\begin{array}{l}\text { Maintaining law and order and protecting the public from harm. Law } \\
\text { enforcement activities may include investigation, prevention, } \\
\text { response, court security, and detention, as well as other associated } \\
\text { capabilities and duties. }\end{array}$ \\
\hline Fire and Emergency Services & $\begin{array}{l}\text { Preventing and minimizing loss of life and property during incidents } \\
\text { resulting from fire, medical emergencies, and other all-hazards } \\
\text { events. }\end{array}$ \\
\hline Emergency Medical Services & $\begin{array}{l}\text { Providing emergency medical assessment and treatment at the scene } \\
\text { of an incident, during an infectious disease outbreak, or during } \\
\text { transport and delivery of injured or ill personnel to a treatment facility } \\
\text { as part of an organized EMS system. }\end{array}$ \\
\hline Emergency Management & $\begin{array}{l}\text { Leading efforts to mitigate, prepare for, respond to, and recover from } \\
\text { all types of multijurisdictional incidents. }\end{array}$ \\
\hline Public Works & $\begin{array}{l}\text { Providing essential emergency functions, such as assessing damage to } \\
\text { buildings, roads, and bridges; clearing, removing, and disposing of } \\
\text { debris; restoring utility services; and managing emergency traffic. }\end{array}$ \\
\hline
\end{tabular}

TABLE 2 Roles and Responsibilities Associated with ESS Specialized Capabilities (DHS 2010a)

Specialized Capabilities

\begin{tabular}{|ll|}
\hline Hazardous Materials Response & $\begin{array}{l}\text { Recognizing and responding to chemical, biological, radiological, } \\
\text { and nuclear incidents; establishing mass decontamination sites; and } \\
\text { protecting the public, the environment, and property during } \\
\text { incidents involving the real or potential release of HAZMAT. }\end{array}$ \\
\hline Search and Rescue & $\begin{array}{l}\text { Providing search and rescue capabilities that can vary significantly } \\
\text { across jurisdictions, from local heavy and technical rescue units } \\
\text { employed for local incidents, to state teams, to the national level } \\
\text { response system. A well-organized structure helps ensure that } \\
\text { coordination and cooperation are achieved and that local and } \\
\text { national needs are addressed rapidly. }\end{array}$ \\
\hline Explosive Ordnance Disposal & $\begin{array}{l}\text { Conducting searches to locate hidden bombs, investigating } \\
\text { suspicious packages, and if necessary, rendering safe any bombs } \\
\text { and ensuring their safe disposal. }\end{array}$ \\
\hline Special Weapons and Tactics and & $\begin{array}{l}\text { Responding to highly dangerous and critical incidents, and } \\
\text { engaging in high-risk services. }\end{array}$ \\
\hline Aviatical Operations & $\begin{array}{l}\text { Providing rapid egress into areas not accessible or not easily } \\
\text { accessible to ground-based assets through the use of highly } \\
\text { sophisticated equipment and helping to identify the scope of, } \\
\text { monitor the progression of, or provide security against an incident } \\
\text { or potential incident that covers great distance. }\end{array}$ \\
\hline Public Safety Answering Points & $\begin{array}{l}\text { Providing public and emergency response communications as well } \\
\text { as a universal emergency telephone number system (9-1-1) to } \\
\text { protect human life, preserve property, and maintain general } \\
\text { community security. }\end{array}$ \\
\hline
\end{tabular}


As reaffirmed by PPD-8, National Preparedness, ESS's progress in building and improving its capabilities to prevent, protect against, mitigate the effects of, respond to, and recover from the threats that pose the greatest risk to national security needs to be tracked (DHS 2011). The final objective is for ESS to improve these capabilities and to propose recommendations and supply guidance that help businesses, communities, families, and individuals with their preparedness planning (DHS 2011).

Although the goal is well defined, questions still remain on how to develop a metric that will integrate ESS's capabilities, roles, and responsibilities. This metric should allow the capabilities of different jurisdictions to be compared and propose options for improving the jurisdictions' postures for consideration.

To address this specific problem, the Infrastructure Assurance Center, in partnership with DHS, has developed an index to characterize ESS's capabilities and a supporting interactive tool — the ESSCI dashboard - to help users evaluate potential options for improving a particular jurisdiction's capability level.

The following sections of this report present the tool, concepts, and the calculation methodology associated with assessing ESS's capabilities. 


\section{CAPABILITIES ANALYSIS METHODOLOGY}

The main objective in developing an emergency services capabilities index is to capture the impact of the ESS on regional or community preparedness and resilience. This task can be complex because directly measuring some variables (e.g., the operational functions of first responders and preventers) can be difficult and time consuming. For example, physically assessing the ability of a local fire protection district to identify and extinguish hot spots at an incident scene might require direct observations of the fire service professionals over an extended period to witness their performance in identifying and extinguishing blazes. For a short assessment process, repeating such an exercise for multiple variables or functions is not feasible.

Continuing on the basis of the above example, a more facile method would be to identify whether the professionals received training and did exercises in which they identified and extinguished hot spots and/or whether they wrote standard operating procedures for such a task. In addition, one might assess the specialized equipment that the responding organization has for carrying out this mission. Although these proxy variables might not always completely define the ability of the fire service professionals to identify and extinguish hot spots at an incident site, the close correlation of these variables to that ability should still accurately depict their capabilities. In addition, measuring a framework that includes planning, training, exercises, procedures, etc. allows researchers to obtain a consistent view of how the organization will function, regardless of who is on duty at the time of an incident. Thus, using these proxy variables allow assessors to conduct the visit more quickly yet still reach valid conclusions.

An appropriate capabilities index would not only assess the ability of the individual ESS disciplines to operate independently but would also allow researchers to evaluate (1) the way in which organizations prepare for and respond to an incident cooperatively, (2) the redundant capabilities of the sector to overcome losses to ESS assets, and (3) preexisting agreements with emergency services organizations outside the jurisdiction to send aid to the region or system should jurisdictional services be lost or overwhelmed.

On the basis of these elements, specific indicators and metrics to assess the ESS capabilities of a specific jurisdiction can be developed. The main objectives are to (1) analyze a community's capabilities in terms of protection, preparation, mitigation, response, and recovery and (2) propose options to increase the community's posture. To accomplish these goals, Argonne, in partnership with DHS, developed a three-step methodology that allows such indicators to be defined for the ESS: (1) information organization and data collection, (2) index calculation, and (3) index visualization and comparison. 


\subsection{INFORMATION ORGANIZATION AND DATA COLLECTION}

The ESSCI structure is based on multi attribute utility theory (MAUT). The capabilities are decomposed into their main attributes, which are then organized into five levels of information, defined by subject matter experts and based on existing standards that constitute an organizational tree. Level 5 information groups the data that need to be collected to calculate the index. Level 4 groups the organization's characteristics, which are defined by the combined Level 5 information. Level 3 groups the organization's capabilities, which are defined by an aggregation of Level 4 information. Level 2 represents the main elements of an organization, which result from aggregations of Level 3 information. Level 1 is built from a combination of Level 2 information; it characterizes the functions that a jurisdiction needs to fulfill to be efficient in terms of its emergency capabilities. Finally, these functions are combined to calculate the overall ESSCI. The raw data that need to be collected constitute the base of the pyramid, and the overall index value is its top. Each level of information is a part of the pyramid, which is characterized by the aggregation of the levels shown in Figure 2.

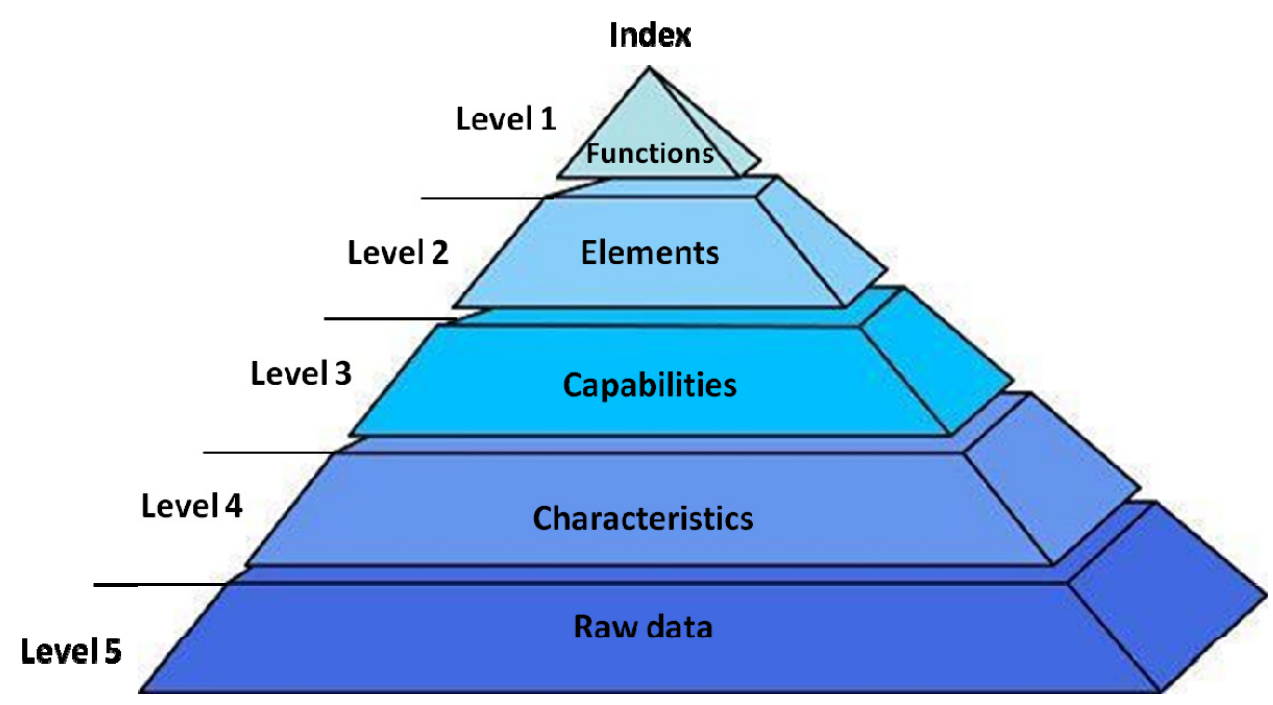

FIGURE 2 Pyramidal Organization of Levels of Information

The overall ESSCI combines eight core Level 1 functions: Emergency Medical Services, Law Enforcement, Fire Services, Search and Rescue, HAZMAT Response, 911/Dispatch (Public Safety Answering Point), Emergency Management, and Coordinating Council/Committee. Each variable that represents a core ESS function captures how well a specific ESS subsector or segment can (1) operate independently of the others in carrying out its prevention, response, and recovery role and (2) operate, plan, and carry out exercises in cooperation with them.

Each of the eight functions, except Coordinating Council/Committee, is made up of two Level 2 elements: Operational Capabilities and Mutual Aid/Assistance Capabilities. The Coordinating Council/Committee function does not analyze assistance capabilities but simply analyzes the 
function of the council or committee that is in charge of coordinating the communities' greater ESS.

The Operational Capabilities element characterizes the potential prevention, preparation, mitigation, response, and recovery activities that the function would be able to provide if required to. The Mutual Aid/Assistance Capabilities element analyzes the ability of the function, through documented preexisting agreements, to either supplement its capabilities if they are overwhelmed or lost, or to expand its capabilities by having agreements in place for specialized staff or equipment. Combining these two variables gives an overall picture of the resources available to a jurisdiction should a potential incident occur.

The Operational Capabilities element is decomposed into Level 3 capabilities. This element groups five capabilities that are common to all eight functions (Facilities/Equipment, Staffing, Training/Exercises, Planning, Communication) along with other capabilities that are specific to a given function.

Thus, the ESSCI combines 8 Level 1 functions, 15 Level 2 elements, and 98 Level 3 capabilities (Table 3). Details on the Level 1, 2, and 3 components are presented in the Appendix.

TABLE 3 Level 1 and 3 Components Constituting the ESSCI*

\begin{tabular}{|ll|}
\hline & \multicolumn{2}{|c|}{ ESS Functions } \\
\hline Emergency Medical Services (13) & Emergency Management (14) \\
\hline Law Enforcement (18) & 911/Dispatch (10) \\
\hline Fire Services (14) & HAZMAT Response (12) \\
\hline Search and Rescue (11) & Coordinating Council/Committee (6) \\
\hline
\end{tabular}

* Number in parentheses denotes number of Level 3components (Operational Capabilities and Mutual Aid/Assistance Capabilities).

The example laid out in Figure 3, which depicts ESSCI's tree organization, follows the Level 1 Emergency Management function. Within Emergency Management, the example looks at the Operational Capabilities element. This element of the Emergency Management function is based on 10 individual capabilities (Level 3), including the Identification of Hazards, which combines three characteristics (Level 4): Hazard Identification Plan, Hazard Risk Assessment, and Hazard Consequence Analysis. The characteristic components combine the raw data collected.

The same organization of information is used for the other capabilities that make up ESSCI. All collected information is then aggregated to calculate an index that represents the capabilities of the ESS to prepare for, respond to, and recover from an event. Thus, when the organization of the different components that characterize the performance of a jurisdiction in terms of emergency services is determined, the next step is to capture the raw data (Level 5). 


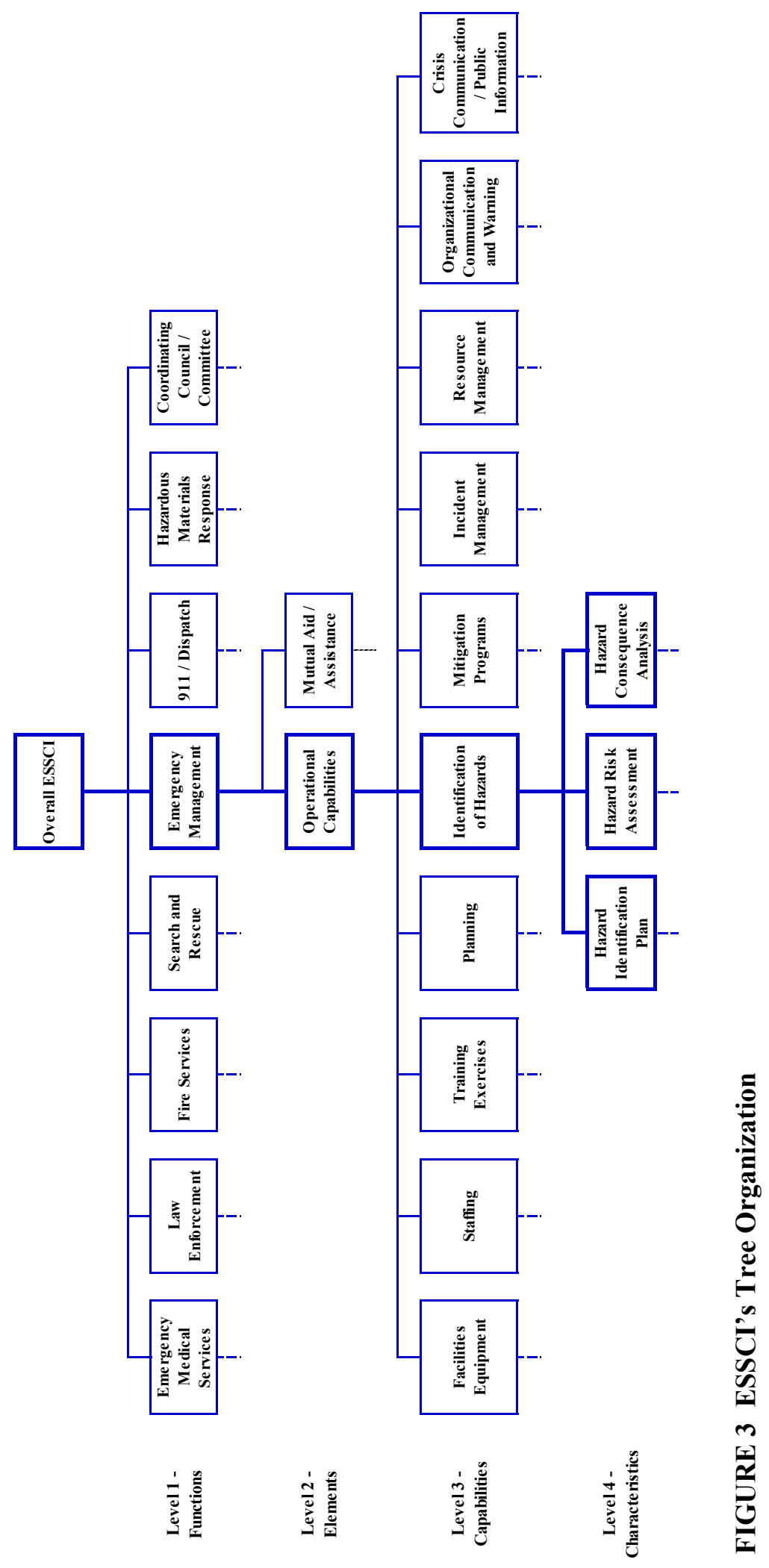


The information required to complete the ESSCI is collected during an on-site assessment visit. However, if deemed appropriate, a self-assessed ESSCI score could also be derived. In this case, the data would be obtained from a survey that corresponds to the variables in the index and could be modified to reflect future changes. Data would be collected through a questionnaire that captures the main information characterizing the capability of emergency services in a specific area to increase that community's resilience (capability to prevent, respond to, and recover from an event). The questionnaire was developed in collaboration with subject matter experts to ensure it captured accurate and transparent information that could be compared and interpreted in a consistent manner. It encompasses more than 300 questions and was designed to be completed by individuals in charge of the various emergency service functions within a community in a limited amount of time. Information collected must be accurate and transparent if it is to yield an effective ESSCI that can be compared with other ESSCIs. Reproducibility is especially critical because an index loses value if it cannot be compared and interpreted in a consistent manner

The next section explains the methodology used to calculate the overall ESSCI.

\subsection{INDEX CALCULATION}

Each question (raw data) and each ESSCI component and subcomponent is assigned a weight representing its importance relative to other questions, components, and subcomponents in its group. The weights were obtained in accordance with the principles of "decision analysis," an approach that helps manage risk in terms of uncertainty (Keeney 1992; Keeney and Raiffa 1976). The methodology is based on a numerical representation of the value pattern, which is obtained by comparing different elements of a jurisdiction and by using the relational terms "better than" and "equal in value to" to define their relative importance. Another important element in this decision analysis tool is the transitivity of the ranking, which means that if element $\mathrm{A}$ is more important than element $\mathrm{B}$, and if element $\mathrm{B}$ is more important than element $\mathrm{C}$, then logically, element $\mathrm{A}$ will be more important than element $\mathrm{C}$. This approach produces a relational representation of a jurisdiction's emergency services alternatives by assigning a numerical value for each of its components.

The weights for a set of components depend on the ranges (worst to best) that are included as options in the question set. Preferences for the specific values within the ranges of single components were provided by subject matter experts via an elicitation process. Table 4 shows an example of the results of that process. It was done by three groups of experts for components of a Hazard Consequence Analysis (this is a subcomponent of Identification of Hazards capability, which is an aspect of the Operational Capabilities of the Emergency Management function).

In the index, the answers to five questions (related to people, first responders, continuity of operations, infrastructure, and economy) are used to characterize the Hazard Consequence Analysis. Each group of experts must rank each of these answers in relation to the others, from 1 (most important element) to 5 (least important). 
TABLE 4 Example of Value Assessments from Experts (Illustrative)

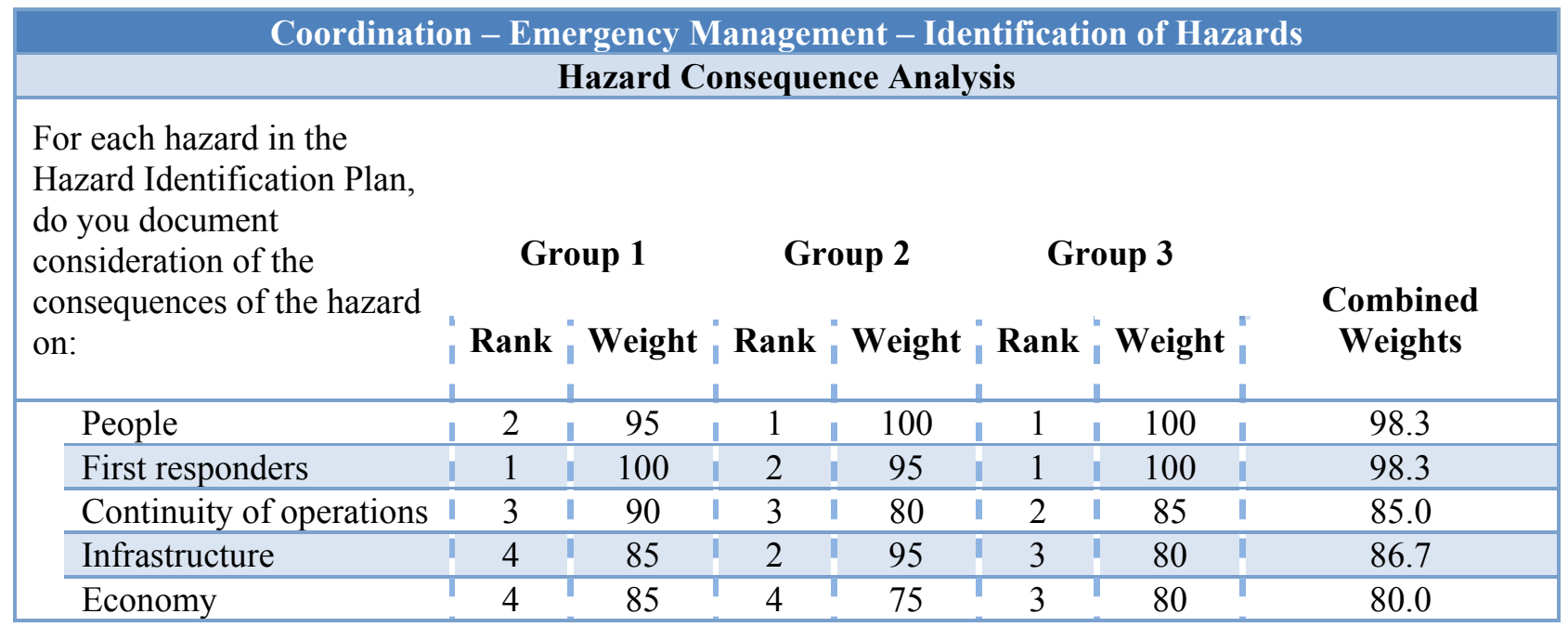

If the subject matter experts determine that two elements have the same importance, they can give them the same rank. Then the element that is ranked first is assigned a weight of 100. Each group defines the weight of each other element of the group, considering its relative rank and importance with respect to the element ranked first. The weights of two elements can be equal if these elements have the same importance, or the weights can be relatively close if the elements are not of equal importance but are separated by only a slight difference in value. Conversely, the difference in weight between two elements can be large if one element is considered significantly less important than the other.

Table 4 shows that the three groups of experts ranked people and first responders as the most important elements to consider in the Hazard Identification Plan. Group 3 thought these two elements have the same importance and ranked both as first. Group 1 ranked first responders as first and people as second, while Group 2 ranked people as first and both first responders and infrastructure as second. Groups 1 and 3 considered infrastructure and economy less important.

However, even though the three groups ranked the variables differently, the weights defined do not vary significantly. Indeed, for this part of the ESSCI, the weights vary only within the range of 75 to 100 , which means that although people and first responders may be considered the most important elements, the other three elements are also considered to be significantly important in producing an optimal Hazard Consequence Analysis.

Finally, when all of the experts' ranks and weights are defined for a specific subcomponent group's level, final weights are obtained by using an average of weights. For the Hazard Consequence Analysis, the final weights vary from 98.3 for the most important elements to 80 for the relatively least important.

The individual variables are arranged in such a way that they can be aggregated up from the raw data stage (Level 4) into broader variables, culminating through the additive process into an 
overall ESSCI value. This value is obtained by using a sum of all the weighted components that characterize the ESS's capabilities that contribute to resilience.

In the example, the answers are not exclusive. The best plan is one that integrates all the components, and it should correspond to a value of $100 \%$. It is then necessary to redefine the combined weights of all plan components to obtain a value of $100 \%$ when they are summed (Table 5).

TABLE 5 Level 4 Hazard Consequence Analysis Index (Illustrative)

\begin{tabular}{|lccc|}
\multicolumn{1}{|c}{ Hazard Consequence Analysis Component } & Weight & Answer ${ }^{\text {a }}$ & $\begin{array}{c}\text { Weighted } \\
\text { Index }\end{array}$ \\
\hline The plan documents consideration of people & 0.219 & Yes & 21.90 \\
\hline The plan documents consideration of first responders & 0.219 & Yes & 21.90 \\
\hline The plan documents consideration of continuity of operations & 0.190 & Yes & 19.00 \\
\hline The plan documents consideration of infrastructures & 0.193 & Yes & 19.30 \\
\hline The plan documents consideration of the economy & 0.179 & No & 0.00 \\
\hline Level 4 Hazard Consequence Analysis Index & & & $\mathbf{8 2 . 1 0}$ \\
\hline
\end{tabular}

${ }^{a}$ Yes corresponds to a numerical value of 100 , and no corresponds to zero.

The emergency management program in the Table 5 example has a Hazard Identification Plan that considers the consequences of the hazards on people, first responders, continuity of operations, and infrastructure. The only consequences not considered are those on the economy. Combining the weighted values of the elements through a summation gives a Hazard Consequence Analysis index of 82.10 (Table 5).

Level 4 characteristics are aggregated into Level 3 capabilities, which represent the core characteristics of each ESS function, such as Facilities/Equipment, Staffing, or Identification of Hazards when associated with the Emergency Management function. For example, the Hazard Consequence Analysis characteristic of Level 4 is one component of the Level 3 Identification of Hazards capability (Table 6).

TABLE 6 Level 3 Identification of Hazards Capability Index (Illustrative)

\begin{tabular}{|lccc|}
\hline \multicolumn{1}{|c|}{ Identification of Hazards Component (Level 4) } & $\begin{array}{c}\text { Level 4 } \\
\text { Weight }\end{array}$ & $\begin{array}{c}\text { Level 4 } \\
\text { Index }\end{array}$ & $\begin{array}{c}\text { Weighted } \\
\text { Index }\end{array}$ \\
\hline Hazard Identification Plan & 0.360 & 50.00 & 18.00 \\
\hline Hazard Risk Assessment & 0.330 & 36.10 & 11.91 \\
\hline Hazard Consequence Analysis & 0.310 & $\mathbf{8 2 . 1 0}$ & $\mathbf{2 5 . 4 5}$ \\
\hline Level 3 Identification of Hazards Capability Index & & & $\mathbf{5 5 . 3 6}$ \\
\hline
\end{tabular}


The Hazard Identification Plan is the most important component of the Identification of Hazards capability; it has a weight of 0.360 . But the weights for all three components are relatively close. The values in this example represent a plan that considers only natural hazards but does not assess the risk of those hazards on government operations or CI facilities. The relative importance (weight) of the Hazard Consequence Analysis is 0.310 . Multiplying the value of the Hazard Consequence Analysis (82.10) by its weight results in a weighted Hazard Consequence Analysis value of 25.45. This value is added to the other weighted components that constitute Identification of Hazards (Level 4) to obtain an Identification of Hazards index of 55.36 (Table 6).

Level 3 capabilities are aggregated to define Level 2 elements. This level represents the two main elements that characterize an overall emergency services function (Operational Capabilities and Mutual Aid/Assistance Capabilities). Identification of Hazards is one of the 10 Level 3 variables that are aggregated to characterize the Operational Capabilities element of the Emergency Management function (Table 7).

TABLE 7 Level 2 Emergency Management Operational Capabilities Index (Illustrative)

\begin{tabular}{|lccc|}
\hline Operational Capabilities Components (Level 3) & $\begin{array}{c}\text { Level 3 } \\
\text { Weight }\end{array}$ & $\begin{array}{c}\text { Level 3 } \\
\text { Index }\end{array}$ & $\begin{array}{c}\text { Weighted } \\
\text { Index }\end{array}$ \\
\hline Facilities/Equipment & 0.1118 & 70.18 & 7.85 \\
\hline Staffing & 0.1148 & 76.47 & 8.78 \\
\hline Training/Exercises & 0.1088 & 25.13 & 2.73 \\
\hline Planning & 0.1088 & 91.68 & 9.97 \\
\hline Identification of Hazards & 0.1059 & $\mathbf{5 5 . 3 6}$ & $\mathbf{5 . 8 6}$ \\
\hline Mitigation Programs & 0.0882 & 86.56 & 7.63 \\
\hline Incident Management & 0.0912 & 32.88 & 3.00 \\
\hline Resource Management & 0.0882 & 34.55 & 3.05 \\
\hline Organizational Communication and Warning & 0.1029 & 88.93 & 9.15 \\
\hline Crisis Communication/Public Information & 0.0794 & 0.00 & 0.00 \\
\hline Level 2 Emergency Management Operational Capabilities Index & & $\mathbf{5 8 . 0 3}$ \\
\hline
\end{tabular}

For the Emergency Management function, the weights of the Operational Capabilities element vary from 0.0794 to 0.1148 . In the example, the community has a full-time, dedicated Emergency Operations Center with a backup that can handle full-scale operations. However, there is no Joint Information Center (index $=70.18$ ). There is a full-time employee who is exclusively designated to serve as the head of the emergency management organization, but there are no dedicated supporting members (index $=76.47$ ). All members who carry out emergency management functions are trained on the emergency operations plan but not on other key plans and procedures. Local and regional exercises had been conducted previously with program stakeholders (index $=25.13$ ). The emergency management program has a comprehensive set of plans, but the plans do not address financial procedures for recovery (index $=91.68$ ). Mitigation programs include procedures for all hazards defined in the Hazard Identification Plan, including 
goals for risk reduction (index $=86.56$ ). The incident management system lacks several elements but includes unified command with multiagency coordination (index $=32.88$ ). The community has a resource management plan but has not conducted a resource gap analysis (index $=34.55)$. The community can use different telecommunication methodologies and warning systems (index $=86.56)$, but there is no documented plan for disseminating or collecting public information (index $=0.00$ ).

The relative importance (weight) of the Identification of Hazards capability is 0.1059 . Multiplying the value of the Identification of Hazards index (55.36) by its weight yields a weighted Identification of Hazards index of 5.36. This new value is added to the other weighted index values that constitute Emergency Management (Level 3 values) to obtain a Level 2 Emergency Management Operational Capabilities index of 58.03 (Table 7).

Level 2 elements are aggregated to define Level 1 functions, which represent the major disciplines of an ESS (Table 8).

TABLE 8 Level 1 Emergency Management Index (Illustrative Asset)

\begin{tabular}{|lccc|}
\hline \multicolumn{1}{|c}{ Coordination Component (Level 2) } & $\begin{array}{c}\text { Level 2 } \\
\text { Weight }\end{array}$ & $\begin{array}{c}\text { Level 2 } \\
\text { Index }\end{array}$ & $\begin{array}{c}\text { Weighted } \\
\text { Index }\end{array}$ \\
\hline Operational Capabilities & 0.800 & $\mathbf{5 8 . 0 3}$ & $\mathbf{4 6 . 4 2}$ \\
\hline Mutual Aid/Assistance Capabilities & 0.200 & 68.52 & 13.70 \\
\hline Level 1 Emergency Management Index & & & $\mathbf{6 0 . 1 2}$ \\
\hline
\end{tabular}

Operational Capabilities is considered the most important element for the Emergency Management function, with a weight of 0.800. The Mutual Aid/Assistance Capabilities element is considered approximately one-fourth as important as the Operational Capabilities element. This would mean that a jurisdiction with the optimal combination of Operational Capabilities but without any documented preexisting Mutual Aid/Assistance Capabilities (i.e., agreements or programs) could achieve a maximum Emergency Management index value of 80.00. On the other hand, a community with no Operational Capabilities but with a full range of Mutual Aid/Assistance Capabilities that were taken into account during jurisdictional planning and regularly exercised could achieve a maximum Emergency Management index value of 20.00.

The relative importance (weight) of Operational Capabilities is 0.800 . Multiplying the value of the Emergency Management Operational Capabilities index (58.03) by its weight yields a weighted index of 46.42. This value is added to the weighted Mutual Aid/Assistance Capabilities element (Level 2) to obtain an overall Emergency Management index of 60.12 (Table 8).

Finally, the eight Level 1 functions are aggregated to define an overall ESSCI (Table 9). The overall ESSCI groups the eight core functions of Emergency Medical Services, Law Enforcement, Fire Services, Search and Rescue, HAZMAT Response, 911/Dispatch, Emergency Management, and Coordinating Council/Committee. Of these, three - Emergency Medical Services, Law Enforcement, and Fire Services — were selected as the most important; each 
received a weight of 0.1626 . The next most important functions are 911/Dispatch, with a weight of 0.1463 , followed by Emergency Management, at 0.1383 . The remaining three functions have a weight of 0.1057 for HAZMAT Response, 0.0732 for Search and Rescue, and 0.0448 for Coordinating Council/Committee.

TABLE 9 ESSCI (Illustrative)

\begin{tabular}{|lccc|}
\multicolumn{1}{c}{ ESS Functions (Level 1) } & $\begin{array}{c}\text { Level 1 } \\
\text { Weight }\end{array}$ & $\begin{array}{c}\text { Level 1 } \\
\text { Index }\end{array}$ & $\begin{array}{c}\text { Weighted } \\
\text { Index }\end{array}$ \\
\hline Emergency Medical Services & 0.1626 & 51.08 & 8.31 \\
\hline Law Enforcement & 0.1626 & 69.72 & 11.34 \\
\hline Fire Services & 0.1626 & 85.27 & 13.87 \\
\hline Search and Rescue & 0.0732 & 47.43 & 3.47 \\
\hline HAZMAT Response & 0.1057 & 16.89 & 1.79 \\
\hline 911/Dispatch & 0.1463 & 74.75 & 10.94 \\
\hline Emergency Management & 0.1382 & $\mathbf{6 0 . 1 2}$ & $\mathbf{8 . 3 1}$ \\
\hline Coordinating Council/Committee & 0.0488 & 26.52 & 1.29 \\
\hline Overall ESS Capability Index & & & $\mathbf{5 9 . 3 0}$ \\
\hline
\end{tabular}

The jurisdiction characterized in the Table 9 example has fairly robust Law Enforcement, Fire Services, 911/Dispatch, and Emergency Management functions, but it only has the services of a HAZMAT response team through mutual aid/assistance agreements. Multiplying the value of the Emergency Management index by its weight (0.1382) yields a weighted Emergency

Management index of 8.31. This value is added to the other weighted index values of emergency services functions to obtain an overall ESSCI of 59.30 (Table 9).

The ESSCI is thus defined by an organization of five levels based on standards that aggregate the data collected. The weights that are used for the raw data (Level 5) to the functional components (Level 1) have been defined by subject matter experts to represent the importance of the components that characterize the capabilities of the ESS. This process results in an overall ESSCI that ranges from 0 (low level of capabilities) to 100 (high) for the jurisdiction analyzed and an index value for each Level 1 through 5 components.

This method of characterizing the capabilities of the ESS of a jurisdiction allows one to consider how the ESS affects the CI and community resilience in its region as well as how capabilities vary within the sector as a whole. A score of 100 on the ESSCI is not necessarily the expected level of capability for an emergency services program. Rather, a score of 100 represents an optimal program, which would rarely be observed. An expected level of capability would come not from a pre-fixed number on the index but rather from an analysis of the average capability score, combined with an examination of minimally accepted capabilities for each of the Level 1 and 2 variables.

In order to improve the resilience of a given jurisdiction, different representations can be used to support decision analysis and to yield options for consideration. 


\subsection{INDEX VISUALIZATION AND COMPARISON}

As shown in Section 3.2, the methodology involves separating the ESS into its component parts and then using a mathematical formula to identify possible decisions that could be made with regard to these parts and to propose different alternatives that might increase a jurisdiction's emergency services capabilities. The methodology helps decision makers by giving them simple and familiar options to choose in the context of a seemingly complex issue.

The ESSCI for a given jurisdiction has significant value. Comparing that index with those of similar jurisdictions to evaluate response capabilities can benefit jurisdiction managers, $\mathrm{CI}$ owners and operators, and DHS.

The data collected can be used and analyzed at different levels. Figure 4 shows the scores for the eight Level 1 ESS functions for a given community. This representation allows for a comparison of the eight functions in blue and the overall community capabilities in red. It highlights the strength of this community in terms of Fire Services and 911/Dispatch. It also shows that the HAZMAT Response and Coordinating Council/Committee functions do not seem to be very well developed or implemented in this community. This visualization of the community functions can support the determination of where efforts should be made to improve.

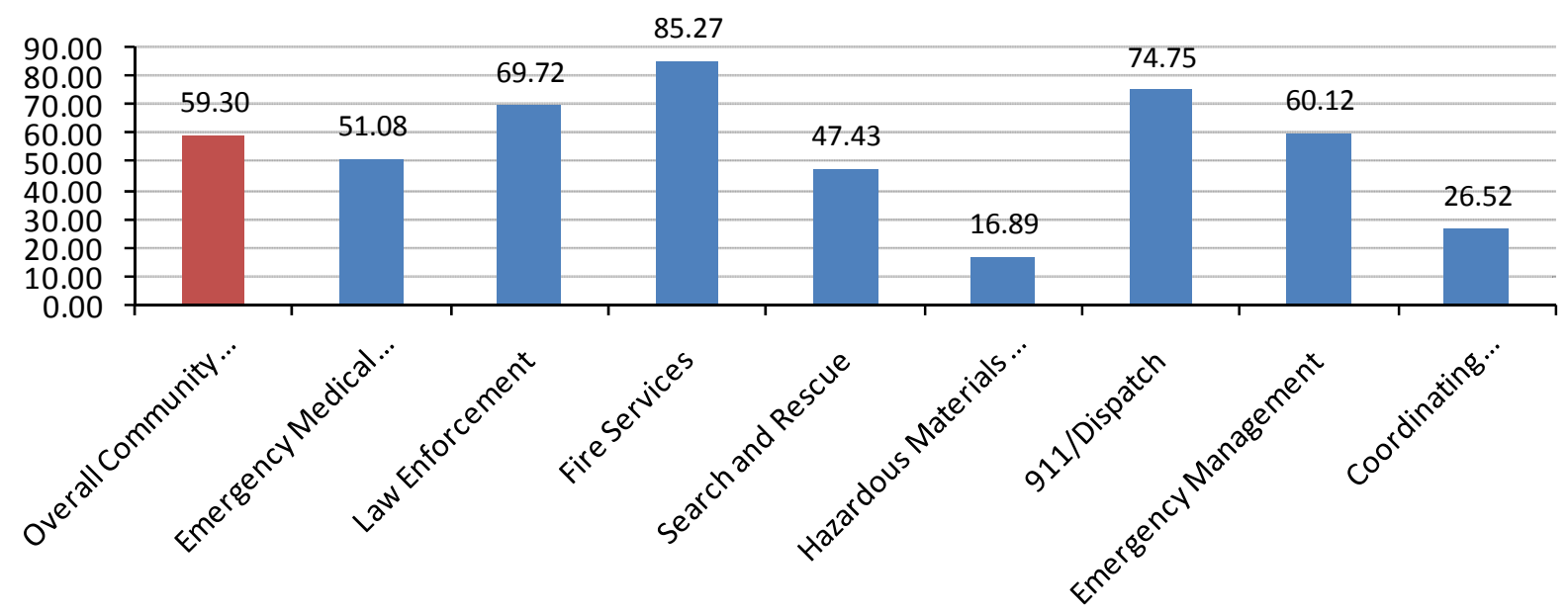

FIGURE 4 Community ESSCI Scores (Illustrative)

It is also interesting to make comparisons at the second level of the ESSCI: the elements level (Figure 5). This type of representation is particularly useful because it shows the capabilities that are possessed or managed by the community as well as the existing agreements that it has with other communities for leveraging outside capabilities. This graph depicts the Level 1 emergency services functions broken down into their two Level 2 elements: Operational Capabilities and Mutual Aid/Assistance Capabilities. The Operational Capabilities element is a measure of the facilities, equipment, staff, plans, and training that the community possesses to fulfill various emergency service missions. The Mutual Aid/Assistance Capabilities element, on the other hand, measures the ability of the community to enhance or supplement its capabilities to prepare for or 
respond to an incident through formalized aid or assistance agreements. As shown in Figure 5, the Law Enforcement function scores a zero for Mutual Aid/Assistance. This can be explained by the fact that the jurisdiction does not currently possess any written mutual aid plans or programs. (In the past, it relied on only informal agreements when assistance was needed.) Conversely, the capability of the jurisdiction to respond to an event involving HAZMAT depends totally on its mutual aid agreements with other communities. The scores for both of the two elements as they relate to the Fire Services function are high, which indicates that the resilience of the jurisdiction in that area is good. The jurisdiction not only has the capability to respond adequately to different types of fire-related incidents, it also has established agreements with other communities that enable it to respond adequately, even if its own response capability is exceeded.

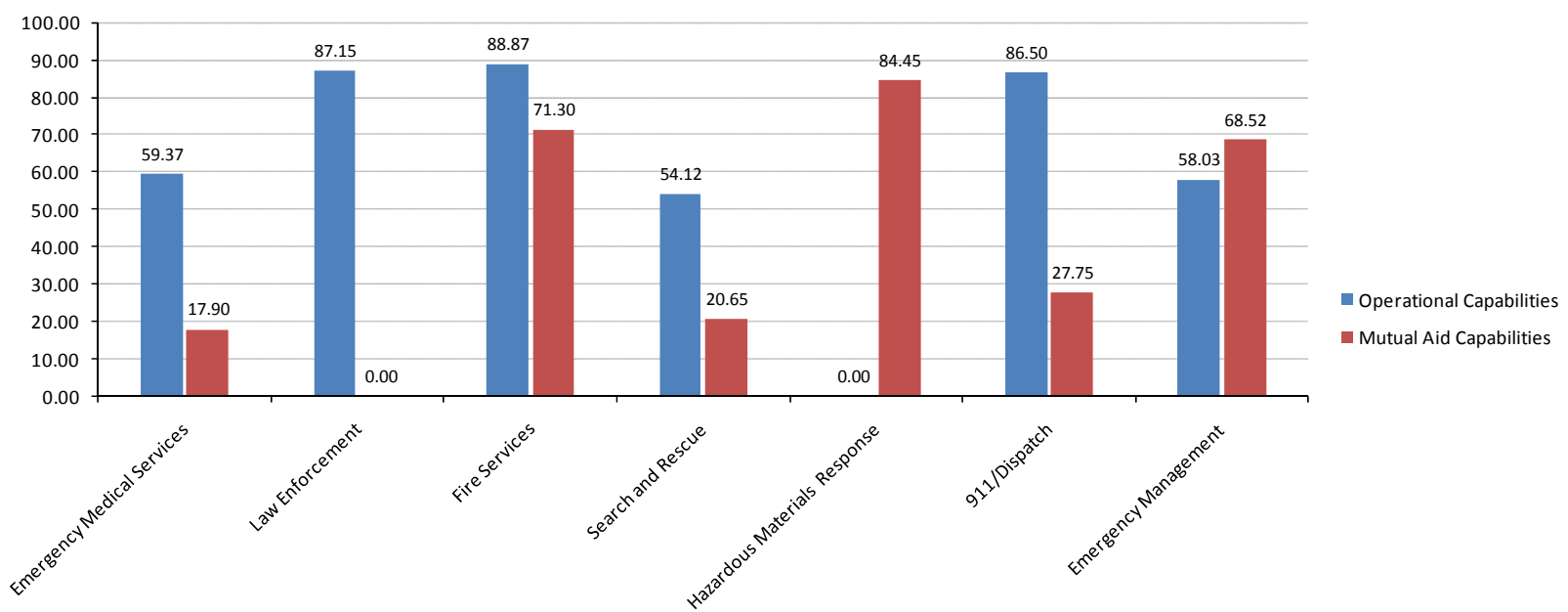

FIGURE 5 Community ESSCI Scores Shown by Element (Illustrative)

The same type of comparison and analysis can be done with the next level of information: the Level 3 capabilities of the ESSCI (Figure 6). This figure shows the scores for the individual operational capabilities measured for the Emergency Management function. They are Facilities and Equipment, Staffing, Training/Exercises, Planning, Identification of Hazards, Mitigation Programs, Incident Management, Resource Management, Organizational Communication, and Crisis Communication/Public Information. The jurisdiction does not have a specific program to inform the public in case of crisis, so the score is zero for that capability. Scores for three other capabilities (Training/Exercises, Incident Management, and Resource Management) are relatively low. Efforts could be made in these areas to improve the jurisdiction's emergency management capabilities.

The information presented in Figure 6 can be combined with the information presented in Figure 7, which shows the relative importance of the elements that contribute to the Operational Capabilities element of the Emergency Management function.

In general, the importances of all the components of Emergency Management in the ESSCI are relatively equivalent. The percentages vary from only $7.94 \%$ to $11.47 \%$. Facilities/Equipment 
and Staffing are the main capabilities of Emergency Management, at $11.18 \%$ and $11.47 \%$, respectively. Crisis Communication/Public Information is the lowest percentage, at $7.94 \%$.

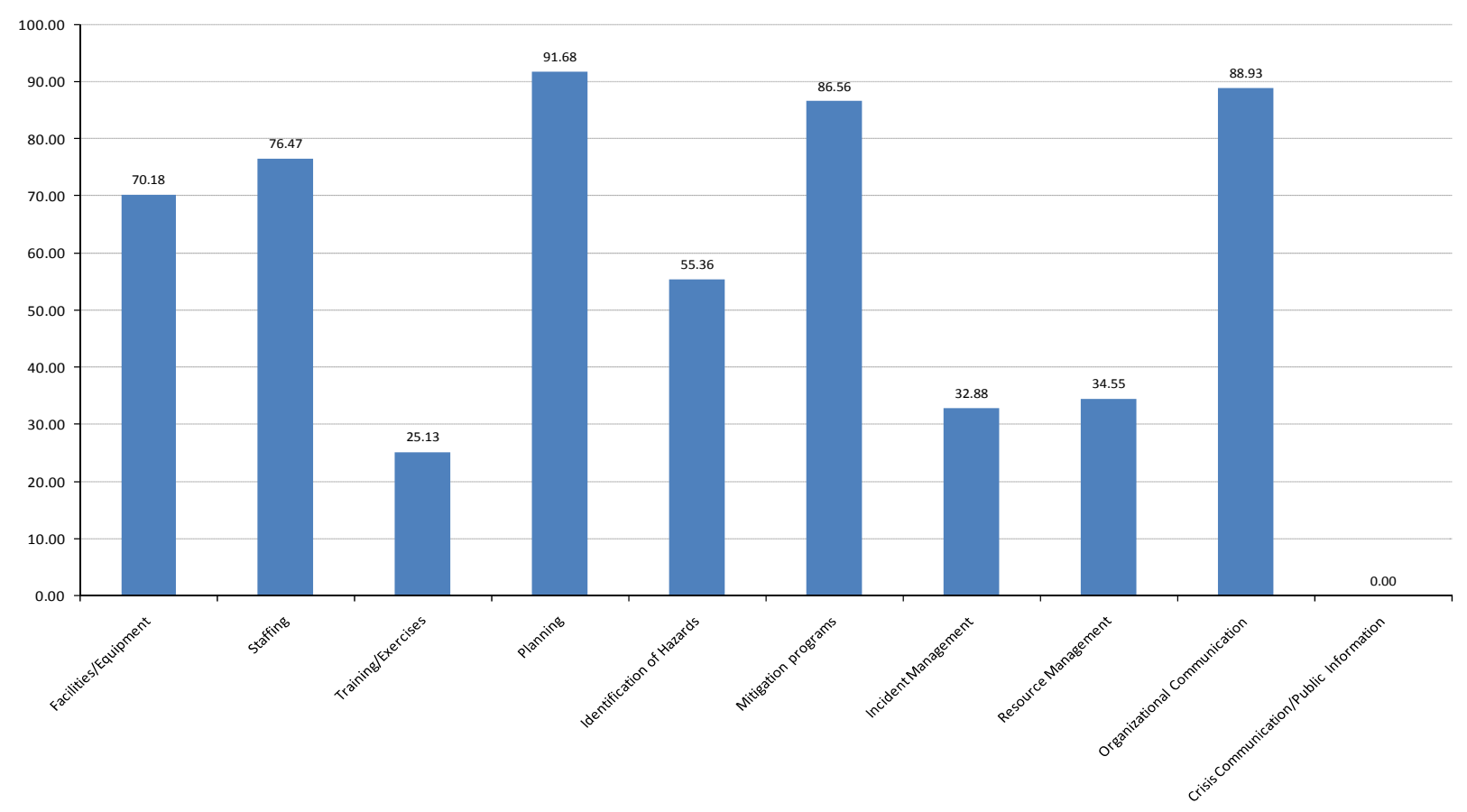

FIGURE 6 Operational Capability Scores for Emergency Management (Illustrative)

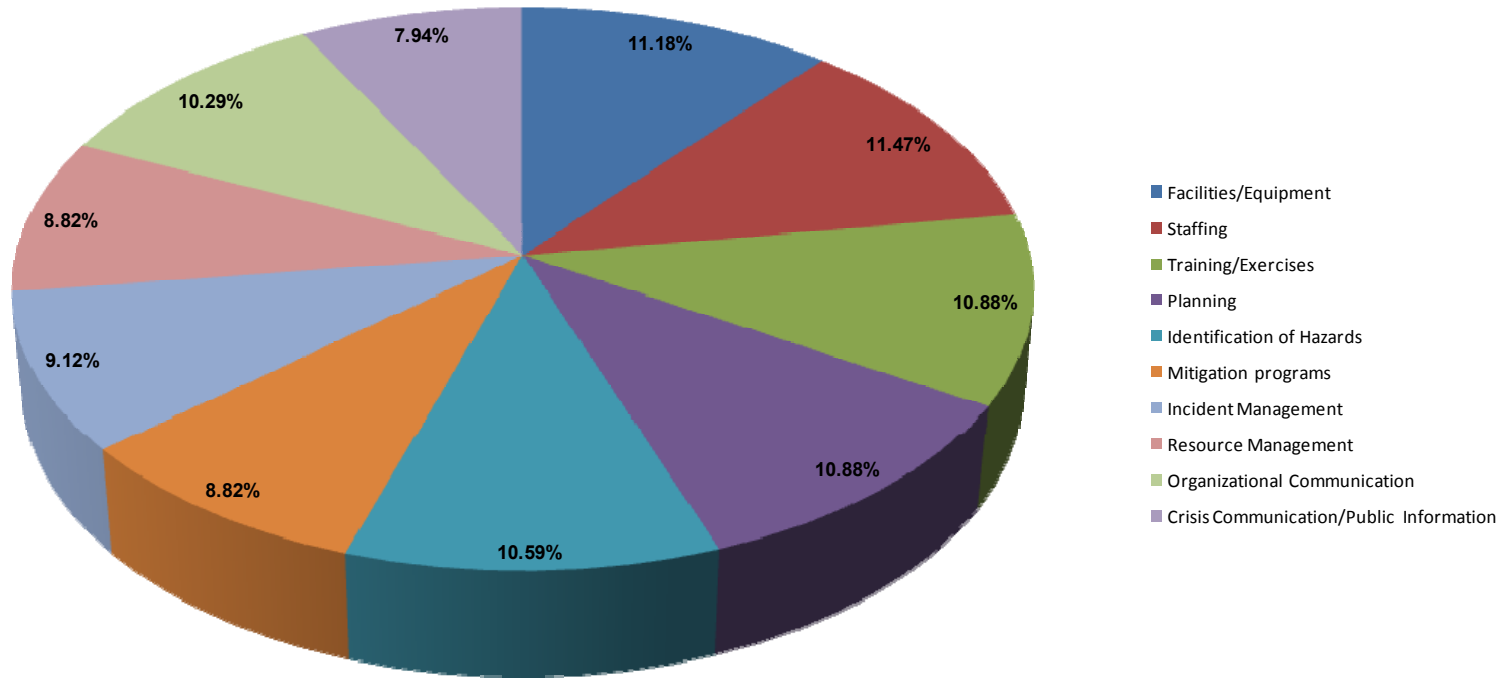

FIGURE 7 Importance of Components with Regard to Overall Emergency Management Operational Capabilities (Illustrative) 
Although an individual ESSCI is important with regard to the data it represents, it can be difficult to fully interpret. Without a frame of reference, the ESSCI's value does not convey its full meaning. For instance, when there is no understanding of the other scores, does an overall ESSCI score of 59.30 lead one to believe that a jurisdiction is well prepared to respond to an emergency? Indeed, the value of an ESSCI is strongly related to the jurisdiction and its environment. A comparative framework is thus necessary. Using an ESSCI value to compare similar jurisdictions with respect to their emergency services capabilities can provide additional vital benefits.

The data that were collected and the indices that were calculated can be grouped in an interactive tool, the ESSCI Dashboard. By making real-time changes to the components considered in the index calculation, the Dashboard can then be used to compare the characteristics of different jurisdictions. Then the ESS will be able to identify the transformational changes that can be implemented as well as their repercussions on emergency services capabilities.

Instead of only one scenario, the Dashboard can allow city or county officials to analyze as many scenarios as needed. This functionality allows them not only to characterize the actual components and measures in place but also to anticipate what changes can be made to improve a jurisdiction's performance in terms of emergency management. This approach is particularly useful for jurisdiction managers because instead of giving them a fixed image of their capabilities, it allows them to define and analyze measures that could be implemented and consider their effects on different ESS capabilities and their efficiency in terms of cost. In addition, they can use the tool to visualize the potential impacts if capabilities are lost as a result of budget reductions or the use of outdated or damaged equipment that is not replaced.

The Dashboard provides different interactive windows that are particularly relevant when emergency management decisions need to be made. The first window is an overview of the overall ESSCI and the functions that constitute the ESS. Figure 8 is an example of this overview screen for five of the nine functions that compose the ESSCI.

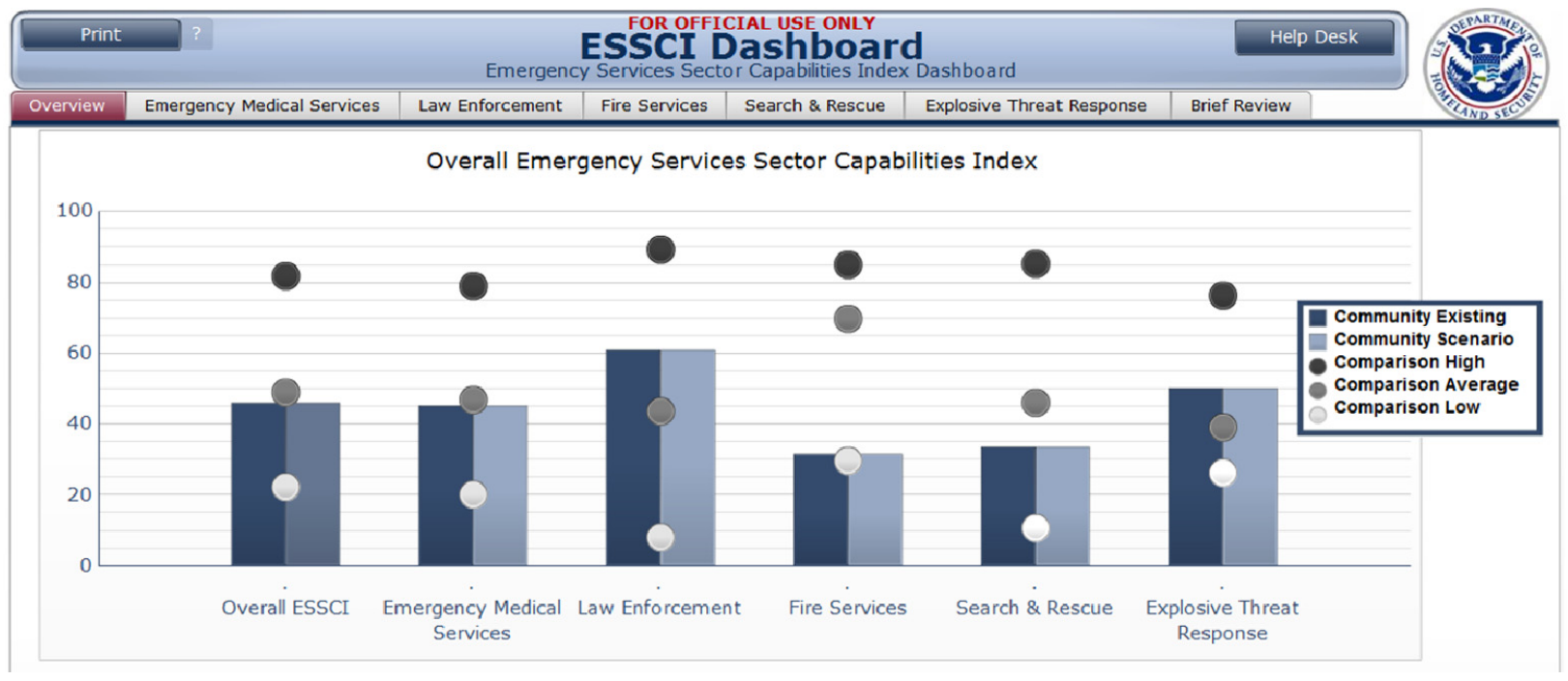

FIGURE 8 ESSCI Dashboard - Overview Screen 
At the top of the Dashboard overview screen, different tabs allow users to select one of the ESS functions, the overview screen, or a brief review. The first tab shows the overview screen. It has bars to represent the values calculated for the overall ESSCI and Level 1 functions. When one of these functions is selected, the related Level 2 and Level 3 components appear in the middle of the screen, which enables the user to choose the different characteristics that apply to her/his jurisdiction. At the bottom of the screen, the user can see - in real time - the repercussions of modifying these components by looking at the different ESSCI values that appear.

Figure 9 is an example of such a window for the Fire Services function. It shows the different options to consider under the Communication tab at the top, and at the bottom of the screen, three counters give the values for the overall ESSCI as well as for the selected function (Fire Services) and element (Operational Capabilities).

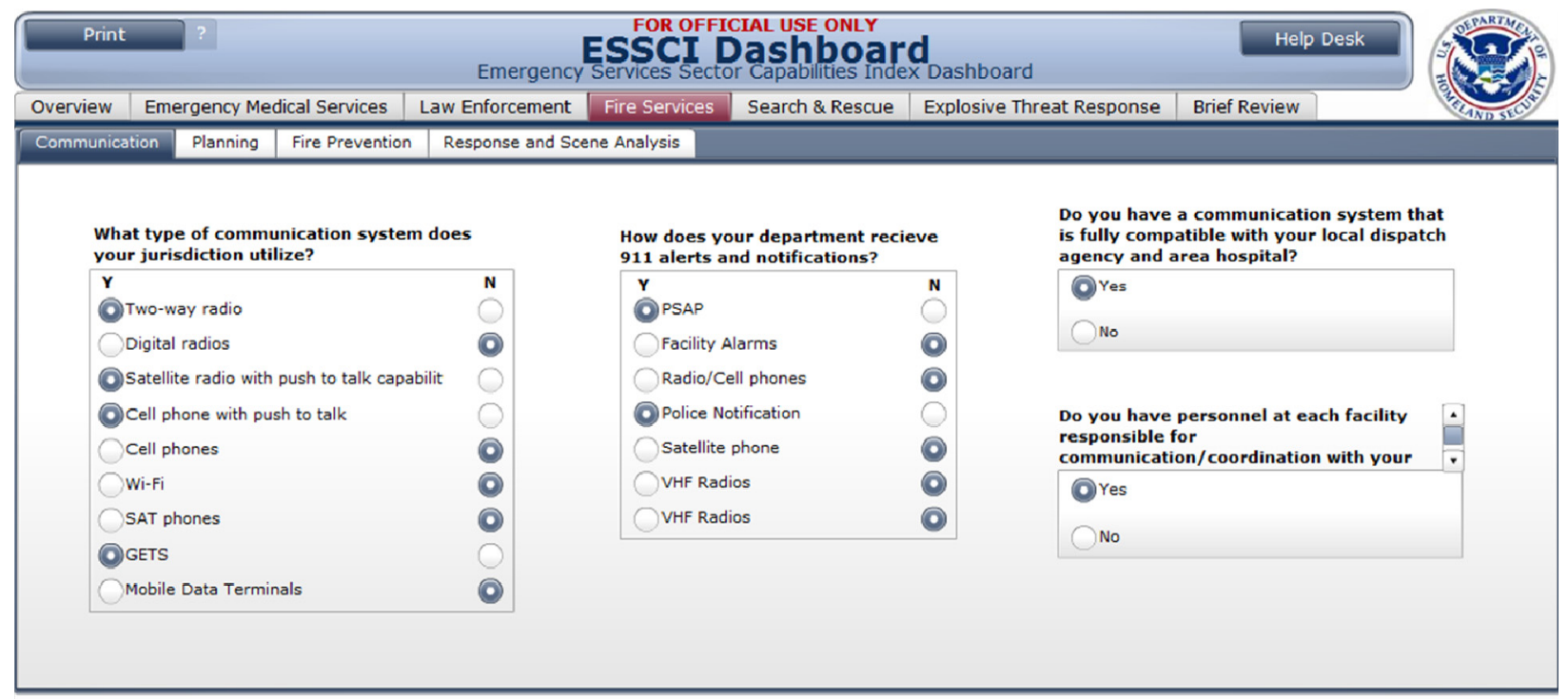
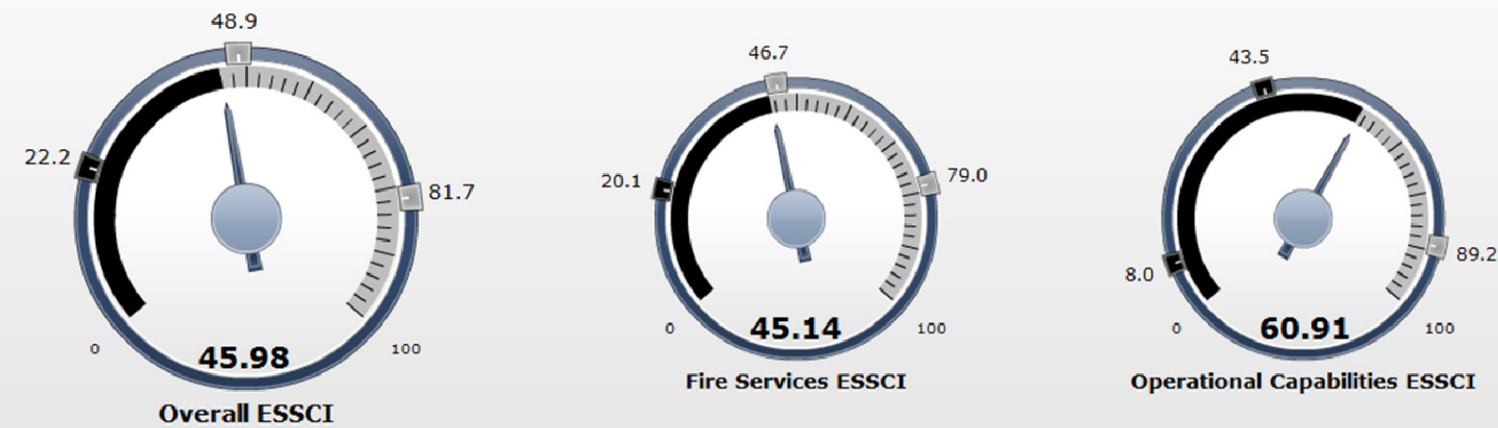

FIGURE 9 ESSCI Dashboard — Fire Services/Communication 
The last type of window in the ESSCI Dashboard (Figure 10) presents a brief review, for each Level 2 element, of the jurisdiction's actual capabilities compared to the average capabilities of similar jurisdictions. This final window allows a comparison between the actual index values of the ESSCI functions and the index values, which represent a specific scenario and the jurisdictional averages.

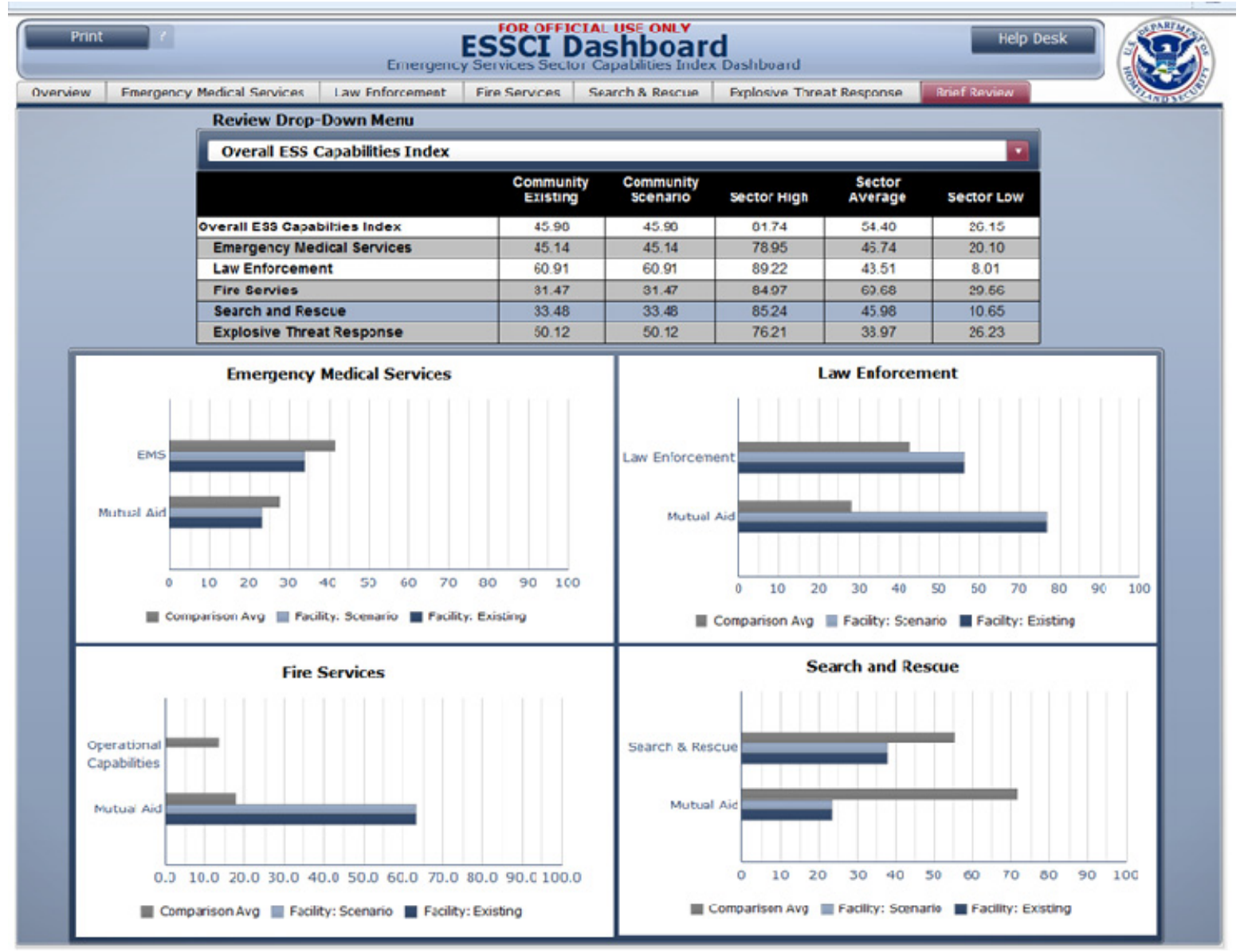

FIGURE 10 ESSCI Dashboard - Brief Review

The Dashboard's features that give users the ability to change parameters and assess different scenarios make it a very powerful tool and particularly relevant with regard to managing ESS capabilities in a given jurisdiction.

The ESSCI, based on a jurisdiction's capabilities in terms of emergency services, is useful when used alone to characterize that jurisdiction's preparedness and response capabilities. It is also useful when integrated into separate programs that characterize the vulnerability and resilience of a region or system. 


\section{INDEX USE}

Community or regional resilience can be defined as the capability of a geographic location's inhabitants and organizations to anticipate the risks and limit the impacts of turbulent change and bounce back rapidly from any impacts (by surviving, adapting, evolving, or growing) (Plodinec 2009). Regional resilience is thus related to the capabilities of a jurisdiction to resist, adapt to, and recover from a disruptive event.

To fully measure regional resilience, all components (e.g., people, institutions, and organizations) must be taken into account. In order to consider all these components, the topic of resilience is often separated into two main aspects for analysis: soft and hard aspects (DHS 2009b). Soft aspects include the capacities of individuals and institutions to adopt and maintain a planning mindset, develop physical and psychological toughness, be self-sufficient, respond appropriately in the face of a disaster, and learn and adapt (DHS 2009b). Hard aspects include the capacities of governments, organizations, and systems to maintain structures and services (i.e., CI assets), recover quickly, shift from degraded to alternative resources, and learn and adapt (DHS 2009b).

The ESS serves a critical role with regard to the soft aspects associated with regional resilience, since it constitutes a community's first line of defense and helps frame the community's mindset. It also plays an integral role in the hard aspects by preventing hazards and reducing the consequences of natural and human-caused hazards (DHS 2010b). Thus, characterizing the ESS is not only an important element in analyzing the overall resilience of a geographic area, it is also vital in protecting and enhancing the resilience of $\mathrm{CI}$ facilities, since it promotes both hard and soft aspects of regional resilience. The ESS is a CI sector that needs to (1) be resilient itself against both natural and manmade hazards and (2) serve as a tool in promoting the resilience of other infrastructures and facilities.

Beyond providing its own benefits, the ESSCI also complements other indices that have been developed by Argonne to assess the protection, vulnerability, resilience, and criticality of facilities when combined with information about the susceptibility of assets to specific threat types (Fisher et al. 2009, 2010). By combining these indices with other programs used by DHS, along with other tools that more specifically assess the soft aspects of regional resilience, we can form more thorough representations of a specific area's resilience and of risk in general. 


\section{CONCLUSION}

In this complex and interconnected world, it is vital to enhance the protection and resilience of society. ESS is a uniquely important sector in that it provides a core function in the emergency management processes used by all CI sectors and the population in general. Its mission is to support the Nation's protection, preparation, mitigation, response, and recovery efforts as it faces manmade and natural hazards.

It is essential to consider this sector's capabilities for fulfilling its roles and responsibilities. The proposed ESSCI, based on accepted programmatic elements, allows one to consider the particular capabilities of ESS to assess, within a global methodology, a region's preparedness to anticipate, absorb, respond to, and recover from a disruptive event. ESSCI was developed to help jurisdictions at different levels (local, state, and national) analyze their capabilities for responding to an emergency. The objective for developing it was to design a better decisionmaking tool that would enable jurisdictions to be compared and that would propose different options for the jurisdictions to consider in order to enhance their preparedness.

The ESSCI tool is also helpful for CI owners and operators, as they can develop and adapt their own security and emergency plans on the basis of what they know about the ESS capabilities of their jurisdiction. It can serve as a basis for defining the domestic efforts that need to be undertaken by all levels of government, by the private and nonprofit sectors, and by the public to build and sustain their preparedness capabilities. It can then support the development of a national preparedness system, by assessing the core capabilities of specific jurisdictions and by identifying possible options that these jurisdictions could implement to improve their preparedness, in agreement with PPD-8.

This specific metric can also be combined with other tools that assess the vulnerability, resilience, and criticality of ESS and other CI assets and thus provide an accurate overview of risk and resilience in a geographic area. 


\section{REFERENCES}

DHS (U.S. Department of Homeland Security), 2008, Infrastructure Taxonomy - Version 3: November 1, 2008, Infrastructure Information Collection Division, Office of Infrastructure Protection, Washington, D.C., http://www.hsdl.org/?view\&doc=133262\&coll=limited.

DHS, 2009a, National Infrastructure Protection Plan: Partnering to Enhance Protection and Resiliency, Washington, D.C., http://www.dhs.gov/xlibrary/assets/NIPP_Plan.pdf.

DHS, 2009b, Concept Development: An Operational Framework for Resilience, prepared by Homeland Security Studies and Analysis Institute, Arlington, Va., for Science and Technology Directorate, Washington, D.C., http://www.homelandsecurity.org/hsireports/Resilience_Task_ 09-01.pdf.

DHS, 2010a, Emergency Services Sector-Specific Plan, An Annex to the National Infrastructure Protection Plan, Washington, D.C., http://www.dhs.gov/xlibrary/assets/nipp-ssp-emergencyservices.pdf.

DHS, 2010b, Emergency Services Sector: Critical Infrastructure and Key Resources, Washington, D.C., http://www.dhs.gov/files/programs/gc_1189094187811.shtm.

DHS, 2011, National Preparedness, Presidential Policy Directive 8 (PPD-8), Washington, D.C., Mar. 30, http://www.dhs.gov/xabout/laws/gc_1215444247124.shtm.

Fisher, R., et al., 2003, Practical Realities in Performing Security Vulnerability Assessments: The DOE/OEA Experience, presented at Homeland Security Conference, National Petroleum Refinery Association, Houston, Texas, March 4.

Fisher, R.E., et al., 2009, Constructing Vulnerability and Protective Measures Indices for the Enhanced Critical Infrastructure Protection Program, ANL/DIS-09-4, Decision and Information Sciences Division, Argonne National Laboratory, Argonne, Ill., Oct.

Fisher, R.E., et al., 2010, Constructing a Resilience Index for the Enhanced Critical Infrastructure Protection Program, ANL/DIS-10-9, Decision and Information Sciences Division, Argonne National Laboratory, Argonne, Ill., Aug.

Keeney, R.L., 1992, Value-Focused Thinking: A Path to Creative Decisionmaking, Harvard University Press, Cambridge, Mass.

Keeney, R.L., and Raiffa, H., 1976, Decisions with Multiple Objectives: Preferences and Value Tradeoffs, John Wiley and Sons, New York, N.Y.

Plodinec, J., 2009, Definitions of Resilience: An Analysis, Community and Regional Resilience Institute, Oak Ridge, Tenn., Nov., http://www.resilientus.org/library/CARRI_Definitions_ Dec_2009_1262802355.pdf. 
The White House, 2003, Critical Infrastructure Identification, Prioritization, and Protection, Homeland Security Presidential Directive 7 (HSPD-7), Washington, D.C., Dec. 17, http://www. ndu.edu/uchs/hspd-7.pdf. 
APPENDIX:

COMPONENTS OF LEVELS 1, 2, AND 3 OF ESSCI 


\section{APPENDIX: COMPONENTS OF LEVELS 1, 2, AND 3 OF ESSCI}

\begin{tabular}{|c|c|}
\hline Emergency Medical Services & Law Enforcement \\
\hline Operational Capabilities & Operational Capabilities \\
\hline $\begin{array}{l}\text { - } \text { Facilities/Equipment } \\
\text { - Staffing } \\
\text { - Training / Exercises } \\
\text { - Planning } \\
\text { - Communication } \\
\text { - Response } \\
\text { - Transportation } \\
\text { - Medical Surge } \\
\text { - Public Education }\end{array}$ & $\begin{array}{l}\text { - Facilities/Equipment } \\
\text { - Staffing } \\
\text { - Training/Exercises } \\
\text { - Planning } \\
\text { - Communication } \\
\text { - Rescue Operations } \\
\text { - Immediate Medical Attention } \\
\text { - Patrol } \\
\text { - Critical Incidents } \\
\text { - Crowd Control } \\
\text { - Crime Scene Investigations } \\
\text { - Accident Investigations } \\
\text { - Detectives } \\
\text { - Record Keeping }\end{array}$ \\
\hline Mutual Aid / Assistance Capabilities & Mutual Aid / Assistance Capabilities \\
\hline $\begin{array}{l}\text { - Type of Agreements } \\
\text { - Coordination of Agreements } \\
\text { - } \text { Mutual Aid Planning } \\
\text { - } \text { Mutual Training / Exercises }\end{array}$ & $\begin{array}{l}\text { - Type of Agreements } \\
\text { - Coordination of Agreements } \\
\text { - } \text { Mutual Aid Planning } \\
\text { - } \quad \text { Mutual Training / Exercises }\end{array}$ \\
\hline Fire Services & Search and Rescue \\
\hline Operational Capabilities & Operational Capabilities \\
\hline $\begin{array}{l}\text { - } \text { Facilities/Equipment } \\
\text { - } \text { Staffing } \\
\text { - } \text { Training / Exercises } \\
\text { - } \text { Planning } \\
\text { - Communication } \\
\text { - } \text { Fire Prevention } \\
\text { - Response \& Scene Analysis } \\
\text { - } \text { Fire Fighting } \\
\text { - } \text { Rescue Operation } \\
\text { - } \\
\text { EMT Certification }\end{array}$ & $\begin{array}{l}\text { - } \text { Facilities/Equipment } \\
\text { - Staffing } \\
\text { - Training / Exercises } \\
\text { - } \text { Communication } \\
\text { - Site Reconnaissance } \\
\text { - Response Procedures / Equipment } \\
\text { - Immediate Medical Attention }\end{array}$ \\
\hline Mutual Aid / Assistance Capabilities & Mutual Aid / Assistance Capabilities \\
\hline $\begin{array}{ll}\text { - } & \text { Type of Agreements } \\
\text { - } & \text { Coordination of Agreements } \\
\text { - } & \text { Mutual Aid Planning } \\
\text { - } & \text { Mutual Training / Exercises }\end{array}$ & $\begin{array}{ll}\text { - } & \text { Type of Agreements } \\
\text { - } & \text { Coordination of Agreements } \\
\text { - } & \text { Mutual Aid Planning } \\
\text { - } & \text { Mutual Training / Exercises }\end{array}$ \\
\hline
\end{tabular}




\begin{tabular}{|c|c|}
\hline Hazardous Materials Response & 911 / Dispatch \\
\hline Operational Capabilities & Operational Capabilities \\
\hline $\begin{array}{ll}\text { - } & \text { Facilities/Equipment } \\
\text { - } & \text { Staffing } \\
\text { - } & \text { Training / Exercises } \\
\text { - } & \text { Planning } \\
\text { - } & \text { Communication } \\
\text { - } & \text { Identification } \\
\text { - Immediate Medical Attention } \\
\text { - }\end{array}$ & $\begin{array}{ll}\text { - } & \text { Facilities/Equipment } \\
\text { - } & \text { Staffing } \\
\text { - } & \text { Training / Exercises } \\
\text { - } & \text { Planning } \\
\text { - } & \text { Reception of calls } \\
\text { - } & \text { Record of calls }\end{array}$ \\
\hline Mutual Aid / Assistance Capabilities & Mutual Aid / Assistance Capabilities \\
\hline $\begin{array}{l}\text { - } \text { Type of Agreements } \\
\text { - Coordination of Agreements } \\
\text { - } \text { Mutual Aid Planning } \\
\text { - } \quad \text { Mutual Training / Exercises }\end{array}$ & $\begin{array}{l}\text { - } \text { Type of Agreements } \\
\text { - } \text { Coordination of Agreements } \\
\text { - } \text { Mutual Aid Planning } \\
\text { - } \text { Mutual Training / Exercises }\end{array}$ \\
\hline Emergency Management & \multirow{5}{*}{$\begin{array}{l}\text { - } \\
\text { - } \text { Advice and Input from Outside } \\
\text { - Stakeholders } \\
\text { - People Incorporated } \\
\text { - Meeting Schedule } \\
\text { - Multi Strategic Plan } \\
\text { Evaluation }\end{array}$} \\
\hline Operational Capabilities & \\
\hline $\begin{array}{l}\text { - } \text { Facilities/Equipment } \\
\text { - } \text { Staffing } \\
\text { - } \text { Training / Exercises } \\
\text { - Idenning } \\
\text { - } \text { Mitigation Programs } \\
\text { - Incident Management } \\
\text { - Resource Management } \\
\text { - Organizational Communication } \\
\text { - } \text { and Warning } \\
\text { Inforis Communication / Public }\end{array}$ & \\
\hline Mutual Aid / Assistance Capabilities & \\
\hline $\begin{array}{ll}\text { - } & \text { Type of Agreements } \\
\text { - } & \text { Coordination of Agreements } \\
\text { - } & \text { Mutual Aid Planning } \\
\text { - } & \text { Mutual Training / Exercises }\end{array}$ & \\
\hline
\end{tabular}


This page intentionally blank 

Argonne

Decision and Information Sciences Division

Argonne National Laboratory

9700 South Cass Avenue, Bldg. 221

Argonne, IL 60439-4844

www.anl.gov 